'medical establishment' or, on the other, sarcastic iconoclasm.

Her analysis of various current issues facing the GMC - its role in influencing the pattern of post-qualification credentials, its ability to deal with incompetent and discourteous doctors, its policy for ensuring continuing competence to treat, the admission of overseas doctors to the Medical Register and the representativeness of its own medical and lay membership (particularly insofar as women, non-white, younger doctors, other health professionals and even alternative healers are concerned) rests on a brief but sound historicallygrounded account in parts I and II of the social factors which have influenced the complex relationships of the profession to its 'customers', the patients, and to the state, since the foundation of the GMC in the mid19th century. Part III, How the GMC works, is based partly on an analysis of documentary sources, partly on interviews with past and present presidents and other members of the council, and partly on her own observations as a member. It provides a convincing account of the way in which the GMC, the epitome of an inherently benevolent elitism, sought to ensure fairness in judging the crimes and misdemeanours of other members of the fraternity while remaining unaware of the extent and nature of its own builtin prejudices, prejudices which may subvert the process of achieving justice for individuals or fairness for entire categories of the profession.

Part IV, The decade of the consumer, assesses the effect of the political and social movements of the 1980 s on the profession and on the GMC. It details the events which led to the referral of the GMC to the Monopolies' and Mergers' Commission and the Office of Fair Trading, as well as the threats to professional dominance which appeared to arise with the official encouragement of consumerism, the growing influence of patients' associations, and the development of alternative therapies able to undermine some of the general public's seemingly obsequious esteem for all orthodox, mainstream biomedical practices, however flimsy their scientific base.

Part V, Fit for the twenty-first century?, contains Professor Stacey's view of the reforms needed to regulate the profession in the future. She recommends an independent enquiry designed 'to look at the entire UK system of regulation of the medical profession as a whole rather than reviewing and reforming its component parts in a piecemeal manner'. She sets out a list of eight criteria which could be used to judge whether the profession was or was not well regulated. Her own suggestions for reform are detailed and include: changes in the composition of the GMC to include more women, more non-white as well as more younger practitioners, and more other health professionals; more patient-friendly measures for hearing complaints about the conduct of doctors; and a greater willingness to loosen the hold of the royal colleges on specialisation and post-qualification education. Above all, she herself believes that, given changes in the composition of the council and in some of its procedures, self-regulation, much modified, can work and is preferable to regulation imposed on the profession from an outside body, which might be considered confrontational or antagonistic by members of the profession. She sees the perennial internal conflict between doctors' self-interest and their service ethic as being played out in the future in changed external circumstances and considers that a new professionalism which lays stress on the latter is both possible and the way forward for those to whom her book is dedicated, namely 'all those practitioners for whom healing the sick and alleviating suffering is their prime goal'.

MARGOT JEFFERYS, Centre of Medical Law and Ethics, King's College, University of London.

\section{Practical medical ethics}

David Seedhouse and Lisetta Lovett, Chichester, John Wiley and Sons, 1992, 134 pages, pb $£ 11.95$

The stated aim of this book is to introduce medical students and doctors to the place of ethics in medical work by teaching what the authors refer to indiscriminately as ethical analysis or moral reasoning. About four-fifths of the text comprises examples and exercises based on case-studies. This is probably the best way of introducing medical ethics and in this instance the material has been well chosen and covers a wide range of problems. The addition in many cases of a clearly separate note on the relevant law is an excellent idea, providing an extra dimension to the discussion in a way that minimises the damage should these sections become dated. However, since the special character of the book derives from the nature and presentation of the moral analysis given in its first fifth, I will concentrate on that in what follows.

In this more abstract material the authors sensibly avoid such familiar theoretical approaches as consequentialism, rights theory or deontology. There is a place for these in a more philosophical treatment, and arguably any serious student should come to understand them, but there is little point in raising them in a work of this kind unless the author is intending to use them. Seedhouse and Lovett are not, and instead make better use of their space by restricting themselves to four points that beginners are likely to find genuinely useful. Firstly, that ethics is not an optional addition to health care but inextricably a component of it. Secondly, that the ethics involved is not esoteric but rather that familiar to us in everyday life. Thirdly, that ethical questions are more than just matters of opinion. Fourthly, that we cannot rely on a straightforward appeal to fixed codes and rules (or indeed any body of uncontroversial ethical standards) for the resolution of our moral problems. I have misgivings only about the last of these points (or more exactly about its elucidation), since under this heading the authors reject the use of 'principles' in medical ethics without noting that in English the term can denote several different kinds of generalisation, so that distinguishing them is a prerequisite of effective criticism

The authors' own approach is simply to provide us with twenty considerations (such as minimising harm, respecting autonomy, the benefits for society and the availability of resources) that are likely to be relevant to any decision. Grouped into four classes, these comprise a useful guide to the complexities of moral problems, and as such constitute something aptly called 'ethical analysis'. They do not, however, constitute a method of moral reasoning. As the authors make clear (page 19), while these are the elements necessary for it, the reasoning must be supplied by the user. It is thus, I think, potentially misleading of them to use the expressions 'ethical analysis' and 'moral reasoning' interchangeably.

Finally, it is vital to mention the form of presentation of the various considerations. They appear first as 
sub-divisions of a multi-coloured square, and reference to these colourcoded boxes is kept up fairly relentlessly throughout the case-studies that follow. As an alternative they also appear in the form of a flow-chart, which ensures that none of the considerations is omitted from our deliberations. The effect of these presentational devices is important. Only if beginners find them useful rather than distracting, and only if they do not mislead readers into supposing that they constitute a method of moral reasoning, can this book be recommended as a lively introduction to medical ethics.

HUGH UPTON, Centre for Philosophy and Health Care,

University College of Swansea.

\section{Philosophy and health care}

Edited by Eric Matthews and Michael Menlowe, Aldershot, Avebury, 1992, viii +229 pages, $£ 35$

This useful collection of papers derives from a conference on medical ethics held in Aberdeen in 1989, but most of the papers have been substantially revised for this publication. Space prevents me from discussing all the papers; I will therefore indicate the scope of the volume and comment on one or two.

The first group of papers is about the rationing of health care. Baruch Brody points to the impossibility of a rational basis for decisions, whether at governmental or at hospital level, and objects to the deceit which tends to be involved in implementing a hospitalbased policy. He advocates encouraging patients themselves to refuse pointless and expensive treatment and/or introducing a voucher system to enable people to choose the kind of health insurance they themselves would favour. These ideas are of course not new, but they are persuasively advocated here. Other papers in this group raise problems about QALYs. S G Potts thinks they are ultimately unjust and tend to advocate euthanasia; Paul T Menzel thinks that while they may represent the scheme which most rational people would consent to (a kind of Rawlsian defence), people might also rationally refuse to put quality enhancement and saving of life itself on the same scale.
A second group of papers concerns the possible rights of fetuses. Here Matti Hayry tackles the thorny problem of how, if at all, a liberal position on abortion can be reconciled with the absolute prohibition of infanticide of normal healthy babies which most people would favour. She argues that prohibiting abortion would be sexist, because it would limit women's 'sovereignty over their bodies' in a way which does not apply to men, whereas prohibiting infanticide is even-handed. This argument is new to me; I do not find it persuasive as stated. If women's sovereignty is to be unlimited, the fetus presumably has no rights; and in that case, there is still a problem in showing how the newborn baby is morally different. True, we can now save it without invading a woman's 'right to choose' - but why must we?

A third group of papers is loosely linked by the topic of letting die, with papers on organ transplants and anencephalic infants; maintaining the brain-dead as 'bioemporia'; criteria for non-treatment of severely handicapped infants; and the social desirability of retaining the prohibition on killing (while allowing some cases of letting die). Christopher Tindall's paper on the brain-dead as bioemporia is striking, but does not seem to me to do justice to the value we place on dignified death and respect for the dead.

In the final paper, Grant Gillett applies Strawson's distinction between objective and reactive attitudes to a discussion of psychiatry. This theme needs clearer handling than it gets in this rather jargon-ridden paper. But it is an important topic, relevant also to the burgeoning activity of counselling. It is refreshing to have one paper at least in a less welltrodden area of medical ethics.

ELIZABETH TELFER, Department of Philosophy, University of Glasgow.

\section{Human needs and the market}

Maureen Ramsay, Aldershot, Avebury, 1992, 221 pages, $£ 35.00$

In this book 'the author maintains that there are universal, objective fundamental human needs, which can be identified empirically, and that the facts about needs have moral and practical implications for action to satisfy them .... Conscious planning to meet needs is advocated since allocation of resources through market mechanisms fails to meet both needs and wants'. There are really two distinct strands to this argument, neither of which depends on the other. The first is whether 'need' is objective and factual, and the second is whether 'need' (when defined) can more effectively be met through market or nonmarket mechanisms. I will consider each strand in turn.

The argument of the book rests on the proposition (page 6) that 'needs may be defined empirically and objectively as means to ends any human being has good reason to pursue, desire or value if they are to act successfully to achieve any end or realise any values, whatever they may be'. It is further argued (page 7) that 'survival is a fundamental human need' as is 'physical and mental health' because 'they are the conditions of any purposive and successful activity' Counter-examples are mentioned but dismissed as exceptions that prove the rule. This leads to the following peculiar statement (page 8): 'We cap choose not to attach any importance te survival and health or to deem othe? goals more important, but this does not lessen their importance'. And although the author says (page 7) that she 'stops short of claiming that from the fact that someone needs something we can establish a right or claim for their having it or for claiming that the need ought to be met', this is precisely what she goes on to do (on page 40) when she writes: 'If $A$ accepts that she has prudential obligations to meet her needs, then logically she must accept that all other agents have equally strong prudential reasons for meeting their own'. Thus (page 41): 'this commits me and every other agent to refrain from interfering with other people's attempts to meet their needs and assisting them in meeting them'. No demonstration is attempted of the assertion that all agents have 'equally strong' (as opposed to 'some') reason to preserve their health (including their survival prospects), and in this formulation of the problem it is difficult to see how the members of a society could ever set about the task of priority-setting when all needs cannot be met, which would be a prerequisite for any 'conscious planning to meet needs'.

This brings us to the second strand of the argument, which is marred by some unnecessarily emotional (and 